\title{
Afinidades Electivas ENTRE GeORG SIMMEL e Natália Correia. Para o Estudo DA RECEPÇÃo De SimMEL EM PORTUGaL
}

\author{
José Luís Garcia \\ (Investigador principal do Instituto de Ciências Sociais da Universidade de Lisboa)
}

A primeira obra de Georg Simmel, traduzida para português e publicada em Portugal, ocorreu apenas em 1969. O livro apareceu sob o título de Cultura Feminina, conta com 197 páginas e é constituído por quatro ensaios de Simmel: "Cultura Feminina", "Filosofia do Coquetismo", "Filosofia da Moda" e "O Masculino e o Feminino". O volume inclui um prefácio de Romeu de Melo e uma introdução de Natália Correia.

Uma pequena editora e distribuidora foi a responsável por esta publicação, a Galeria Panorama, dirigida por António Lima Rodrigues. As traduções surgem assinadas por A. de Aguiar, sem que seja declarado de que idiomas foram vertidos os textos, embora Lima Rodrigues indique que a política editorial da Galeria Panorama era a da tradução directa das respectivas línguas. A tiragem da Cultura Feminina (1969) foi de 4000 exemplares, a sua impressão ficou a cargo da Bertrand (irmãos) Lda e a distribuição foi também da responsabilidade da Galeria Panorama. Esta editora caracterizou-se por um registo transversal de géneros literários, com publicações do romance à poesia, obras de cariz filosófico, mas também a ficção científica, o policial e o western. Disso são testemunho a pluralidade abrangida pelas séries editadas: Cultura Clássica, Autores Portugueses, Teatro, Poesia, Biografias, Antologia, entre outras. A Cultura Feminina insere-se na série Cultura Contemporânea.

O responsável pela publicação de Cultura Feminina, para além de editor, foi também livreiro, director de um jornal regional, galerista e escritor de contos policiais e não só, tendo convivido com várias figuras literárias do seu tempo. Justifica a criação da editora, na década de 60 , 
com o conhecimento pessoal das difíceis condições de publicação em Portugal na altura. O primeiro contacto com as obras e a selecção com vista à publicação era estabelecido através de uma agência literária.

Romeu de Melo, autor do prefácio de seis páginas, nascido em 1933 e falecido em 1991, foi economista de formação, ensaísta, tendo trabalhos publicados em domínios tão heterogéneos como a filosofia, cultura e ficção científica. São conhecidas ligações deste autor ao movimento surrealista. É considerado um precursor da ficção científica no universo literário português ${ }^{1}$. No prefácio que Romeu de Melo assina na Cultura $\mathrm{Fe}$ minina apresenta, de modo informado, aspectos biográficos de Simmel e identifica a genealogia do seu pensamento filosófico e sociológico. Refere várias das suas obras fundamentais, como Schopenhauer e Nietzsche, de 1906, a Sociologia, de 1908, ou o ensaio sobre Goethe, de 1916. Esboça sumariamente algumas coordenadas fundamentais do pensamento simmeliano, apontando a orientação existencialista que nele se entrevê, assim como a proximidade ao criticismo neo-kantiano. Estabelece o quadro geral do pensamento sociológico de Simmel, em que a sociedade surge não como substância, mas como tecido de interacção humana, viva e fecunda. A fecundidade que pauta a vida, nas suas múltiplas expressões, e que Romeu de Melo assume como "centro irradiante da filosofia de Simmel". Ausente fica qualquer nota introdutória relativamente à Cultura Feminina e restantes ensaios, omissão que Romeu de Melo justifica para passar a palavra a Natália Correia.

Natália Correia, colaboradora permanente de Lima Rodrigues na Galeria Panorama, nasceu nos Açores a 13 de Setembro de 1923 e morreu em Lisboa a 16 de Março de 1993. Como é bem sabido, Natália Correia tem uma extensa e valiosa obra literária; é uma das principais poetisas portuguesas do século XX. Teve uma actividade cívica intensa, com manifestação política, e formulou um pensamento singular sobre a questão feminina que abrange uma perspectiva de antropologia filosófica. A introdução que Natália Correia realizou aos ensaios de Simmel sobre a situação da mulher, as relações entre os sexos e o amor não são uma mera peça protocolar de uma escritora sobre um pensador alemão relativamente desconhecido. Natália Correia mostra-se verdadeiramente interessada nas perspectivas de Simmel sobre o universo feminino, e neste plano ela emparceira com outras feministas destacadas, como a socióloga Marianne Weber ou a médica psiquiatra e psicanalista alemã Karen Horney.

${ }^{1}$ Entre os títulos legados por Romeu de Melo contam-se, por exemplo, A evolução humana, de 1965, o romance A buzina, de 1972, Ensaio sobre a Cultura, de 1978, Introdução à liberdade, de 1979, Reflexões, em dois volumes, um de 1981 e outro de 1986. 
Natália Correia, Romeu de Melo e Lima Rodrigues eram parte de um círculo cultural em que se moviam poetas, cineastas e ensaístas como Dórdio Guimarães, José Carlos Ary dos Santos, David Mourão Ferreira, Bernardo Santareno, João Rui de Sousa, entre outros. Natália Correia foi uma figura feminina de destaque e elemento agregador deste círculo de intelectuais e artistas.

Que a primeira obra de Simmel surgida em Portugal tenha como tópico central a situação das mulheres e tenha aparecido sob o estímulo de um círculo cultural e de uma poetisa e defensora da emancipação feminina tão reconhecida como Natália Correia, no final dos anos 60, é um acontecimento que certamente justifica uma reflexão sobre esta conjuntura do processo de recepção dos ensaios de Simmel no nosso país.

\section{II}

Neste artigo, não se tem a ambição de proceder a uma completa e exaustiva teoria da recepção do pensamento de Simmel em Portugal. Não se procura indagar a extensão da sua influência nas ciências sociais, nem identificar os agentes e os centros de difusão. A motivação que orienta o presente texto não é, assim, explorar possíveis filiações autorais da produção académica em Portugal, ou canais secundários de acolhimento do pensamento do autor germânico. A genealogia da recepção de Simmel em Portugal é uma tarefa que obrigaria a um investimento de pesquisa mais aprofundado $^{2}$.

O horizonte de análise aqui adoptado é muito mais restrito: partindo dos dados disponíveis, que sugerem uma recepção tardia e um débil património de tradução, a intenção é explorar uma das vias da introdução do pensamento de Simmel em Portugal. Far-se-á alusão à realidade conhecida em Portugal, fortemente contrastante, por exemplo, com a de Espanha. Tal mapeamento, sumário e preambular, procura contextualizar a linha de recepção privilegiada.

Em termos de publicação de uma obra sua em língua portuguesa, não foi através do meio universitário que Simmel chegou primeiramente aos leitores portugueses. A sua recepção é realizada pelo núcleo cultural reunido em redor de Natália Correia e numa pequena editora. Simmel escreveu extensamente sobre cultura, estética, figuras do mundo da arte como Goethe e Rembrandt, e conviveu com os círculos culturais e artísticos da sua época em Berlim. A filosofia poder-se-ia ter interessado pela

${ }^{2}$ Em língua portuguesa, tendo como foco a recepção de Simmel no contexto académico brasileiro, tal empreendimento foi já realizado por Leopoldo Waizbort (2007). 
sua figura e reflexão; no entanto, não existem muitos vestígios dessa curiosidade nos meios filosóficos portugueses até quase à década de 70 . Esta situação poderá certamente ser relacionada com as dificuldades da filosofia num período de censura e ditadura, totalmente avesso a um pensamento que não se perfila com os principais postulados do mundo científico e ideológico da época, e com tópicos filosóficos não convencionais. A excepção conhecida, no que diz respeito a uma certa recepção por parte da filosofia em Portugal, é a segunda publicação de uma obra de Simmel para português, que aconteceu no ano seguinte ao da Cultura Feminina, através da edição de Problemas Fundamentais da Filosofia (1970). A responsabilidade desta publicação coube também a uma pequena editora de Coimbra, a Atlântida, com tradução directa do alemão realizada por Inah Oliveira do Amaral Aguiar, que se apresenta como licenciada em filologia germânica. A tiragem foi de 3250 exemplares.

Que tenham sido editoras de pequena dimensão e um círculo literário e artístico a dar início à publicação dos ensaios de Simmel em português tem também certamente muito que ver com os contextos de interdição da sociologia na universidade portuguesa durante a ditadura do Estado Novo. A tardia recepção de Simmel em Portugal conjuga-se ainda com as dificuldades do seu próprio perfil intelectual, que viu o acesso a um posto universitário ser sucessivamente contrariado, e só o pôde alcançar quatro anos antes da sua morte. Simmel foi um teórico que sofreu as adversidades e a desconsideração dos que, na instituição universitária, acreditavam ser depositários e garantes da identidade académica. Compreende-se, pois, que a sua figura e pensamento não pudessem ser facilmente recebidos nos meios universitários portugueses, aliás, tal como aconteceu na própria Alemanha.

O desinteresse por Simmel dos meios universitários e filosóficos portugueses contrasta vivamente com a recepção por parte da filosofia do país vizinho, onde Shopenhaeur y Nietzsche, de 1907, foi traduzida para castelhano por José R. Pérez-Bances e publicada logo em 1915³. Em 1926-27, um dos dois grandes trabalhos que Simmel dedicou explicitamente à Sociologia, Soziologie. Untersuchungen über die Formen der Vergesellschaftung, foi publicado com o título de Sociologia: estúdio sobre las formas de socialización pela Revista de Occidente, igualmente traduzido por José R. Pérez-Bances. Em 1934, Cultura feminina y otros ensayos surge na mesma revista, tendo cada um dos ensaios tradutor próprio: "Cultura Feminina" por Eugenio Imaz, "Filosofía de la coqueteria" por José R. Pérez-Bances, "Lo masculino y lo feminino" por M. G. Mo-

${ }^{3}$ Esta obra em castelhano contou com uma segunda edição editada na Argentina em 1944, uma terceira em 1950 e, mais recentemente, duas outras - uma em 2004 em Espanha, e outra em 2005 na Argentina. 
rente, e "Filosofía de la moda" por Fernando Vela. Este último que assumirá, já em 1946, a tradução de Problemas fundamentales de la filosofia, novamente para a Revista de Occidente. Fundada em 1923 por José Ortega y Gasset, esta revista caracterizou-se desde os primeiros números por uma atenção sistemática a correntes do pensamento centradas nas problemáticas do mundo moderno e na recepção de autores alemães, que Ortega tinha conhecido na sua passagem pela universidade alemã. A recepção espanhola de Simmel está directamente ligada à influência que o autor alemão exerceu no pensamento de Ortega y Gasset. De facto, Ortega teve como mestre directo Simmel que, para a geração de 1914 na Alemanha, foi uma das grandes personalidades intelectuais que encarnou o ambiente espiritual daquela época. Simmel foi um transmissor directo do pensamento de figuras centrais das ciências humanas da Alemanha, como Dilthey, e sobretudo foi um criador de múltiplas noções, termos, problemas e ideias que se tornaram um diagnóstico da modernidade e foram prosseguidos por vários discípulos estrangeiros de grande envergadura.

Algo que se impõe reflectir é, no marco da penúria de textos de Simmel traduzidos em Portugal, a persistência para a republicação no nosso país dos seus ensaios em torno da "cultura feminina", do amor e da moda. Com efeito, 35 anos depois, os textos do livro Cultura Feminina, de 1969, voltaram a ser objecto de tradução em duas outras publicações. Maria João Costa Pereira começa por editar a colectânea de estudos de Simmel Fidelidade e Gratidão (2004a), onde assina um prefácio de treze páginas e a tradução de "A Coquetterie", "Fidelidade e Gratidão", "Sobre a Sociologia da Família", "As Metrópoles e a Vida Mental", "O Estrangeiro", "O Segredo" e "A Aventura". O volume inclui também "A Moda" e a "Cultura Feminina", com tradução de Michael Knoch. Mais tarde, ainda em 2004, surge um novo conjunto de ensaios de Simmel, igualmente com prefácio e traduções de M. J. Costa Pereira, sob o título Fragmento sobre o amor e outros textos (2004b). Neste livro incluem-se os textos "Algumas reflexões sobre a prostituição no presente e no futuro", "O papel do dinheiro nas relações entre os sexos", "Fragmento sobre o Amor", "Nota sobre o Eros platónico e o Eros moderno", "Fragmentos e aforismos".

Posteriormente, Artur Morão edita o livro Filosofia da Moda e Outros Escritos (2008), onde volta a surgir a tradução a partir do alemão de "Filosofia da moda" e "Psicologia da coqueteria", num volume que inclui o ensaio "Psicologia do adorno". Artur Morão assina uma introdução intitulada "A moda como sintoma antropológico em Georg Simmel", bem como uma cronologia da vida de Simmel e uma bibliografia das suas obras. Não se encontra qualquer referência de Artur Morão às edições precedentes dos ensaios de Simmel, sendo que as traduções de M. J. Cos- 
ta Pereira eram também omissas relativamente à publicação de Cultura Feminina em 1969, ao prefácio de Romeu de Melo e à introdução de Natália Correia.

O círculo cultural de Natália Correia, e, em particular, ela própria, tinha o que Goethe chama wahlverwandtschaft, uma afinidade espiritual electiva com algumas das mais importantes expressões do pensamento e do temperamento de Simmel. Este parece ser verdadeiramente o caso da afinidade de Natália Correia com certas perspectivas simmelianas sobre a lógica da vida, a dinâmica da cultura moderna e a situação das mulheres. É possível que o teórico alemão tenha exercido algum tipo de influência em certas ideias singulares da poetisa portuguesa, mas esta interpreta-as de modo livre, de acordo com inclinações já anteriormente assumidas. Neste sentido, não sabemos se o que Natália Correia faz não é de alguma forma atribuir uma genealogia para o seu próprio pensamento. Todavia, é relevante que a escritora se tenha comprometido no trabalho de divulgação e apresentação de um autor que não estava ainda publicado em Portugal.

Será, talvez, pertinente lembrar o investimento simbólico que a sexualidade recebia, no contexto da época da publicação em Portugal de Cultura Feminina. No plano internacional assiste-se à reivindicação feminina do prazer, exigência indissociável de um fluxo mais vasto de reformulação dos quadros valorativos da intimidade e das relações entre os sexos. Ainda que, em plena década de 60 , os ecos da revolução sexual em curso no mundo ocidental estivessem longe de ser tão sonoros como noutros países europeus, o certo é que a sociedade portuguesa não estava completamente imune aos movimentos de radicalização da altura.

Em muitos dos circuitos de oposição interna, das franjas ideológicas oposicionistas e dos movimentos de cultura de resistência ao regime, a sexualidade era um continente em processo de politização, associado à expressão contestatária e potencial de fractura com o tecido ideológico dominante. $\mathrm{O}$ fenómeno de então contrasta com a tendência contemporânea, onde parece vigorar o impulso para a integração das sexualidades heterodoxas nas estruturas, códigos e linguagens rituais hegemónicas. A expressão política da sexualidade enquanto potencial de destabilização do convencional parece ter dado lugar, hoje, a uma certa aspiração à própria convenção por parte das minorias.

Foi, precisamente, no contexto de politização da sexualidade dos anos 60 que Natália Correia contribuiu "para a modificação de muitos comportamentos, sobretudo na valorização do feminino e do erótico, em termos assumidamente e fecundamente provocadores", na expressão de David Mourão-Ferreira, citado por Maria Teresa Horta (1993). O poeta acrescen- 
ta: "O auge disso mesmo foi a publicação da 'Poesia Erótica e Satírica' em 1965, que a levou ao banco dos réus, onde a acompanhei por ser autor das badanas e de uma das poesias objecto de indignação" (Horta 1993).

\section{IV}

Natália Correia inicia a sua introdução à Cultura Feminina de Simmel com a consideração de que os ensaios do autor alemão nos revelam "um dos mais penetrantes esforços para interrogar auspiciosamente a esfinge da feminilidade" (1969: 13). O elogio de Natália Correia reflecte o seu reconhecimento sobre três aspectos relevantes que podem ser encontrados no pensamento de Simmel sobre a questão feminina. Em primeiro lugar, a abertura a uma antropologia feminina, cuja matriz de formulação não deverá ser o pensamento lógico, mas antes a assunção autónoma do conteúdo próprio da feminilidade. Em segundo, o reconhecimento da criatividade de tal conteúdo, traduzida na edificação de uma "nova aquisição cultural". Por último, indo ao encontro do que Natália Correia identifica como fundamento teórico da "cultura feminina", a "demonstração da unilateralidade do abstracto da nossa cultura", a exposição do seu viés de constituição patriarcal.

Natália Correia sublinha a antinomia simmeliana entre os sexos. $\mathrm{O}$ espírito masculino, escreve, apreende a verdade de forma fragmentária, por cisão estrutural com o mundo que conhece; por seu turno, a feminilidade, cujas estruturas de cognição operam por união com as coisas, recebe a verdade sob a forma total da sabedoria: "enquanto para o homem, cuja actividade espiritual se processa em dois planos, a verdade surge em termos de conhecimento, pressupondo uma operação intelectual tendente ao conhecimento da verdade, ou seja, o conhecimento probante da lógica, para a mulher, cujas faculdades cognoscentes se exercem em comércio actual com as coisas, a verdade identifica-se com a sabedoria" (Correia 1969: 14).

A relação do homem com o mundo é de ocupação, esvaziamento, conquista. O mundo não lhe pertence; ele está de fora, conhece-o com a frieza laboratorial do cirurgião, ao passo que a mulher é criatura imersa no mundo. Por isso a sabedoria lhe é própria, estado que descreve como "estado sófico de participação no todo". O conhecimento, de matriz masculina, é produto da cisão e da clivagem entre sujeito e mundo, operada pelo conceito. Cita Simmel, afirmando ser este o sentido patente na afirmação de que o homem é "um ser de relatividade", enquanto a mulher é "propriamente o ser humano" (Correia 1969: 14).

É, precisamente, a "natureza unitária" da mulher, a sua indivisibilidade anímica, o seu mergulho total no mundo, que a impede de se adaptar 
a uma cultura de objectivação que lhe será sempre menor. Racionalidade a que é estrangeira, porque diferente, porque maior; é a insuficiência da racionalidade masculina, operada por cisões e rupturas com o mundo, que a afasta - e não uma pretensa incapacidade que desqualificaria a mulher perante os seus pares masculinos, no círculo de produção da ciência e do conhecimento. A mulher tem a experiência total do mundo; ela vive "em comunidade afectiva" com as coisas (Correia 1969: 15). Natália Correia mostra-se claramente consonante com a perspectiva diferencialista que Simmel desenvolveu algumas décadas antes.

A poetisa portuguesa considera que o âmago teórico da "cultura feminina" desmistificaria o irracionalismo alegadamente caracterizador da mulher: "o fundamento da tese de Simmel, denuncia a falsidade dos velhos narizes de cera anti-feministas, tais como a falta de lógica e o irracionalismo da conduta mental da mulher" (Correia 1969: 14).

Se na introdução à Cultura Feminina Natália Correia desenvolve um conjunto de reflexões de fundo sobre a condição da mulher, na verdade, a disposição para a problemática da emancipação das mulheres atravessa toda a sua obra escrita e o seu trabalho, o que inclui a sua actividade poética, ficcional, publicista (nos jornais e na televisão) e política, como deputada e não só.

O feminismo sui generis de Natália Correia, tão particular que o próprio conceito levanta questões - Maria Teresa Horta caracteriza-o como "feminismo encoberto, que jamais assumiu" (2003) - caracteriza-se essencialmente pela recusa dos meios formais, dos corredores da política estabelecida, com vista à correcção das assimetrias classicamente repressoras da figura da mulher. Tal correcção é, aliás, afastada por Natália Correia, quando efectivada pela horizontalização e homogeneização dos dois géneros: "Tenho presente um mundo que, pela estúpida desfeminização da fúria reivindicativa da mulher, corre o risco de homogeneização. Copia a mulher o homem para se libertar, copia-o no pior". E o pior para Natália Correia é "donjuanismo machista", o "delírio profissional da produtividade", o "activismo fanático das ficções políticas", a fixação no "que separa, não no que une". Porque, para Natália Correia, "o que une é a diferença. A maravilhosa diferença, como afirmou algures, que gera o amor que torna possível a vida", afirmou num discurso da Assembleia da República de 1991. Também nesta questão sobressai a proximidade com a grande articulação dialéctica por onde flui a vida, segundo Simmel: o que une, cuja forma é a ponte, e o que separa, metaforizada na porta. O curso da nossa vida humana, para Simmel, processa-se por formas em ponte e formas em porta. A ponte liga o que está separado; a porta divide o que está unido. Também o pensar segue este curso. Pensar é unir, mas igualmente separar, para novamente associar, e voltar a cindir (Simmel 2001 [1909]). 
A não subordinação feminina ao imperialismo da razão; a subtracção feminina aos esquemas mentais das leis da lógica e da aridez do conceito, condenam-na ao fracasso, quando posta em rivalidade com o homem. E por isso Natália Correia considera que a disputa feminina pelas prerrogativas do homem encerra uma condenação ao malogro, à menoridade, ao eterno desajuste: "o feminismo, concebido como caricatura dos privilégios viris, foi uma traição feita à mulher", diz (2003: 146). É esse o erro último do feminismo militante, politizado: reivindicar a entrada da mulher numa cultura feita para o homem, à sua imagem, criada para o servir.

$\mathrm{O}$ seu pensamento sobre a questão feminina caracterizava-se pelo repúdio da mimetização e da competição com o homem enquanto processo de emancipação da mulher. Relativamente ao projecto de que à mulher caberia entrar no mundo da política estabelecida para, no seu interior, desenvolver as suas ideias e a sua acção, Natália Correia pensava que tal só poderia fazer com que ela se submetesse a padrões ameaçadores da sua natureza e cultura. Esse projecto tornaria a mulher numa cópia daquilo que já era nocivo nos homens. "Acho que não vale a pena a mulher libertar-se para imitar os padrões patristas que nos têm regido até hoje", sustentou Natália Correia (Sousa, Ponte, Guimarães e Soeiro 2004: 65). Ao que acrescenta: "Ou valerá a pena, no aspecto da realização pessoal, mas não é isso que vem modificar o mundo, que vem dar um novo rumo às sociedades, que vem revitalizar a vida" (Sousa, Ponte, Guimarães e Soeiro 2004: 65). Por isso, o feminismo, ainda balizado nas estruturas de poder e domínio em que classicamente se efectiva o masculino, não seduz Natália Correia. O feminino não deve impor-se numa lógica concorrencial, mas de complementaridade com o masculino, nutrindo o mundo, não o conquistando: "Há quem pense, e talvez com certa razão, que a mulher deve entrar no mundo da política para, dentro desse universo, desenvolver as suas ideias e a sua acção. Mas eu penso que quando uma mulher entra nesse mundo, ela própria é obrigada a submeter-se a padrões que ameaçam toda a sua natureza, a natureza da sua cultura. Ela é levada a transigir, tornar-se numa cópia daquilo que já é mau nos homens. Eu penso que a acção da mulher deve desenvolver-se fora da política do Poder. Uma acção política de contra-poder. Pela recusa" (Sousa, Ponte, Guimarães e Soeiro 2004: 67).

Também aqui ressalta a sintonia com o modelo alternativo de Simmel. Este não postula acolher a mulher na dimensão objectiva da cultura, fazendo-a participar nela com o homem no processo criativo dos produtos culturais, mas sim fomentar equivalência entre a feminilidade e a subjectividade. Não se trata de sancionar o status quo, colocando a mulher no plano da cultura objectiva dominante da sociedade, o que só levaria à infra-valorização feminina, e sim de modificar a dinâmica mais vasta do processo cultural. 
Segundo Simmel, a cultura objectiva é essencialmente masculina: não apenas o comércio e a ciência, a arte e a indústria, a administração estatal e a religião são criações do homem, mas, diferenciadas em esferas de valor autónomas, elas impõem e exigem uma especialização acentuada e uma fragmentação excessiva da pessoa, que são alheias à natureza feminina. Ora, como bem assinala Waizbort, "[s]e os homens construíram historicamente uma cultura, Simmel tem claro que se trata de uma cultura masculina, na qual a contribuição da mulher é, pode-se dizer, nula. A ideia radicalizada de uma igualdade de direitos significa portanto a defesa de uma cultura feminina como outra face do existente" (2000: 259). Tal empreendimento, afirma o mesmo autor, impõe "desenvolver e descobrir actividades que são próprias às características femininas" (Waizbort 2000: 260).

Entre tais actividades encontram-se, por exemplo, a interpretação da história, o exercício da medicina, da arte teatral e da produção literária. Não se trata apenas de alargar o círculo da produção da cultura, de integrar as mulheres nas comunidades artísticas, de as admitir e respeitar enquanto sujeitos criadores. Trata-se, sim, de estimular as formas culturais cujo dispositivo criador seria a feminilidade, o que resultaria num acervo de novas manifestações, plásticas, literárias, cénicas e científicas.

Esta questão encontra-se bem elucidada num artigo de Teresa Sousa Fernandes (1993) sobre a assimetria dos sexos em Simmel, quando argumenta que o autor alemão se distancia "dos principais pólos do debate contemporâneo, centrado agora nos efeitos (negativos ou positivos) da participação massiva das mulheres na vida cultural", por considerar que tal debate "privilegia a quantidade de valores reproduzidos ou assimilados, ignorando o problema fundamental - a possibilidade de criação de valores especificamente femininos". Isto porque Simmel considera que um alargamento das fronteiras culturais poderia proceder das mulheres na medida em que apenas elas estão em condições de produzir o que os homens não podem produzir (Fernandes 1993: 29).

Natália Correia aproxima-se da tese de Simmel na rejeição de uma cultura uniformizadora de homens e mulheres, aniquiladora das diferenças que vê como específicas. Esta ideia é ainda salientada por M. J. Costa Pereira, quando afirma que Simmel se mostra "contrário ao 'igualitarismo brutal' entre os sexos, que considerava sinónimo de empobrecimento pela via da uniformidade. Valoriza as diferenças, embora afirmadas não numa guerra dos sexos para a qual as mulheres partiriam antecipadamente derrotadas pelas desvantagens que decorrem da sua condição de base desigual" (Pereira 2004b: 17).

Para Simmel, a mulher é qualitativa e fundamentalmente diferente do homem: homogénea e pouco diferenciada, centrada e fechada sobre si mesma, incapaz de desprendimento emocional, todo o seu ser se opõe à 
diferenciação funcional das sociedades modernas. O posicionamento teórico sobre os predicados constitutivos do feminino, e a sua demarcação face ao masculino, leva à partilha, por Simmel, de "pressupostos essencialistas", para usar uma expressão de Frédéric Vandenberghe (2005: 173). Neste entendimento, a "cultura feminina" de Simmel exprime uma demarcação dos feminismos de tipo liberal e socialista, ambos radicados na valorização da igualdade dos sexos, para se aproximar de um feminismo diferencialista.

Também Natália acredita que a diferença entre homens e mulheres é constitutiva, deve ser preservada e dignificada, mas consubstanciada num novo sistema de relação. Considera existirem efectivamente dois princípios constitutivos do mundo, a que correspondem duas mundividências distintas: "Penso que vamos entrar numa fase de conciliação, de harmonia, de combinação, chamemos-lhe assim, das categorias características do pensar e do sentir masculino com a mundivisão da mulher. Penso que vai haver uma combinação para estabelecer um equilíbrio" (Sousa, Ponte, Guimarães e Soeiro 2004). Novamente se encontram aqui ecos de Simmel. A sua proposta - preconizada nos ensaios sobre os sexos, a questão feminina e o amor - é, seguindo palavras de M. J. Costa Pereira, "um modo de convivência entre os sexos definido pela complementaridade e a cooperação de duas culturas de género, por oposição à supremacia ou à substituição de uma pela outra, onde o feminino não se define pela competição ou pela imitação do modelo masculino, mas pela invenção de formas alternativas, especificamente femininas de ser e de fazer" (2004b: 17).

Há, no tratamento da questão dos sexos por Natália Correia, a conjugação com outros âmbitos do seu pensamento, relativos à demanda de revitalização e repaganização do mundo. Natália Correia afirma que toda a mulher é "um translado da Mãe Eterna", paradigma de fertilidade e "fonte cultural da mulher". Por isso, designa de matrismo a sua orientação teórica no domínio da emancipação feminina: "É no paradigma da Grande Mãe que vejo a fonte cultural da mulher; por isso lhe chamo matrismo e não feminismo", sustenta (Sousa, Ponte, Guimarães e Soeiro 2004: 65).

Para a poetisa, é precisamente o desajuste, a inadequação, o "mal-estar feminino" provocados por uma cultura que apelida de exclusivamente masculina, objectiva, afim do progresso tecnológico e científico (paroxismos do génio masculino, na sua visão), que abrem a possibilidade de um horizonte de mudança. Ao revelar a crise total deste arquétipo, a consciência feminina é a possibilidade de edificação de uma "nova sociedade": erguida sobre os escombros da razão absolutizada, uma cultura viva pode finalmente impor-se, pelo compromisso e "reajustamento do sentimento e da razão", escreve (Correia 1969: 16-17). A mesma ideia 
aparece quando afirma que "a mulher deve seguir as suas próprias tendências culturais, que estão intimamente ligadas ao paradigma da Grande Mãe, que é a grande reserva, a eterna reserva da Natureza, precisamente para os impor ao mundo ou, pelo menos, para os introduzir no ritmo das sociedades como uma saída indispensável para os graves problemas que temos e que foram criados pelas racionalidades masculinas" (Sousa, Ponte, Guimarães e Soeiro 2004: 65). Por isso, o arquétipo do masculino - da racionalidade analítica, da aridez do conceito, da razão estéril e da beligerância - é, para Natália Correia, um modelo falhado. A "masculinização" da mulher só agudiza este declínio.

Existem, para além dos diversos pontos de contacto identificados, outras confluências entre o pensamento de Simmel e o ideário de Natália Correia, assim como da sua expressão biográfica. É possível estabelecer diversas correspondências entre os dois vultos, a despeito das décadas que os separam e dos contextos culturais específicos que os acolheram. E, se tais diferenças de época e contexto são inegáveis, certo é que lhes era transversal uma situação de menoridade, legal e social, da mulher. Ora, se o quadro ideológico do Estado Novo é conhecido, a situação que Simmel enfrentou também estava evidentemente muito longe da simetria social entre os sexos: "Simmel assinala a necessidade de se garantir a independência das mulheres no novo código civil, de se abrir as instituições de ensino às mulheres (ele foi um dos primeiros docentes, na Prússia, a aceitar alunas em suas aulas), de se lhes permitir o exercício de profissões várias, de se garantir a mesma remuneração para homens e mulheres para os mesmos serviços", lembra Waizbort, (2000: 261).

De forma próxima à sua ponderação sobre a cultura feminina, Simmel desenvolveu uma filosofia do amor. A exemplo da religião, da arte e da ciência, Simmel concebe o amor como uma forma cultural que pode hospedar em si todos os conteúdos do mundo, e associá-los numa concepção erótica do mundo. Categoria primacial, o amor possibilita uma forma sensual-afectiva ao existente, imprimindo o seu traço na totalidade do outro, indo contudo muito para além do que pode ocorrer entre dois seres humanos, abarcando a totalidade dos conteúdos possíveis deste mundo. O amor busca o seu objecto, fixando nele o poder criador do espírito erótico, e pode moldá-lo de diversas formas; mas o amor pode não ter destinatário, pois não deriva do que é amado, antes dirige-se para o que se ama.

$\mathrm{O}$ amor, assim compreendido como modalidade de relação com o mundo, e não como produto de uma relação dual, oferece similitudes com 
a perspectiva da poetisa, revelada em afirmações como "a missão da mulher é assombrar, espantar", "de resto, não é só a mulher, todos os seres humanos têm que deslumbrar os seus semelhantes para serem um acontecimento. Temos que ser um acontecimento uns para os outros." O elogio da vertigem radica numa exigência de que "a vida seja um motivo de deslumbramento". "[Se] chama a isso sedução, cumpri aquilo que me era forçoso fazer" (Sousa, Ponte, Guimarães e Soeiro 2004: 70).

A personalidade e o pensamento de Natália Correia são avessos ao ascetismo desencarnado, à censura do deleite, do sensualismo em sentido amplo. Assim se compreende, também, a afirmação de que "não temos o direito de continuar a crucificar a ideia de Cristo num sofrimento eterno. (...) Temos de o trazer à vida, por isso as mães têm que descer dos montes, para lhe pôr na mão o tirso da alegria, para ele retornar à Vida com toda a embriaguez de que encheu os evangelhos", já que foi Cristo que "transformou a água em vinho" (Sousa, Ponte, Guimarães e Soeiro 2004: 68).

Estas expressões de transgressão, em ruptura com convenções e códigos de censura social, encontram eco na concepção simmeliana da existência autêntica e da lei individual. Note-se que, para Simmel, Goethe é o modelo do que entendia por "uma existência autêntica", compreendendo por isto um indivíduo que ousa ir mais além das normas sociais da época, que se abre à aventura pelos saberes perigosos e que busca ultrapassar os seus próprios limites, louvando a felicidade da transformação que a beleza do mundo nele operou (Simmel 1913). No universo simmeliano, o espírito transgressor tem como moldura o desprendimento e a confiança; é uma forma de entrar em sintonia com um mundo em permanente devir, destruição e renovação.

O lugar da transgressão não é o eu consciente, mas o âmbito anímico, a alma. É no pensar que isto primeiramente acontece, porque o pensar se relaciona primeiramente com a sensibilidade e o afectivo, e só depois com o entendimento, a consciência, e o conteúdo definido. Simmel é um pensador que procura compreender a simbiose, a conjugação crucial entre pensamento e sensibilidade.

Simmel analisa a cultura moderna como estando inscrita numa dinâmica que desemboca num destino trágico, manifestado no facto de que a cultura se objectiva e emancipa dos sujeitos, voltando-se contra eles para os alienar. Articula com este diagnóstico uma filosofia da vida segundo a qual o fluxo quente da vida só pode exprimir-se através de formas rígidas que abafam o seu elã e congelam a sua expressão no convencionalismo. A filosofia da vida de Simmel é inseparável da sua filosofia da cultura, e ambas subentendem e inspiram uma perspectiva crítica do indivíduo no mundo moderno. Embora já tarde na sua vida, Simmel elaborou uma Lebensphilosophie (filosofia da vida) unificadora, que considera todas as obras e estruturas da cultura como produtos de diferentes 
formas e experiências humanas. É neste ponto que a questão feminina intersecta diversos pontos da filosofia simmeliana. Como nota Waizbort, "a ideia de 'cultura feminina' permite a Simmel explorar o momento utópico da sua filosofia da cultura, pois se trata, então, de uma cultura radicalmente diferente da existente" (Waizbort 2000: 260).

$\mathrm{Na}$ esteira da filosofia moral propugnada por Stirner, a lei individual de Simmel, cuja compreensão exige a interpelação da filosofia da vida do autor alemão, assume-se em certa medida como dispositivo individualizado de normatividade. A pluralidade, irredutível a uma instância uniformizadora, é inabarcável por imperativos universalizantes que postulem tal uniformidade. Por isso Simmel propõe não uma lei universal, que, no sistema kantiano, manteria a validade apesar de qualquer determinação epocal ou espacial, mas um princípio que preserve e exprima o dinamismo vital da própria lei.

A realidade portuguesa é pobre na publicação e no estudo crítico dos ensaios e do pensamento de Simmel, sendo por isso pertinente constatar que existam várias versões publicadas dos seus textos sobre a situação das mulheres e sobre temas muitas vezes associados ao mundo feminino, como o amor e a moda. É igualmente digno de observação que tenham sido personalidades femininas, como Natália Correia, M. J. Costa Pereira e Teresa Sousa Fernandes, a comentá-los. Será que podemos falar de uma recepção feminina de Simmel em Portugal, na ausência prolongada de um pujante interesse académico?

\section{Bibliografia}

Correia, N. (1969). "Introdução", in Georg Simmel, Cultura Feminina. Alfragide: Galeria Panorama.

Correia, N. (2003). Breve História da Mulher e Outros Escritos. Lisboa: Parceria A.M. Pereira Livraria Editora.

Fernandes, T. S. (1993). "Assimetria dos sexos e construção do mundo social na teoria de Georg Simmel", in Sociologia. Problemas e Práticas, n. ${ }^{\circ} 13$, pp. 19-38.

Horta, M. T. (2003). "Prefácio", in Natália Correia, Breve História da Mulher e Outros Escritos, Lisboa: Parceria A. M. Pereira Livraria Editora.

Horta, M. T. (1993). "Natália Correia - Uma Mulher de Coragem", Marie Claire, n. ${ }^{\circ}$ 55, Maio de 1993.

Pereira, M. J. (2004a). "Prefácio", in Georg Simmel, Fidelidade e Gratidão e Outros Textos. Lisboa: Relógio D’Água.

Pereira, M. J. (2004b). "Prefácio", in Georg Simmel, Fragmento Sobre o Amor e Outros Textos. Lisboa: Relógio D’Água.

Simmel, G. (1969). Cultura Feminina. Alfragide: Galeria Panorama.

Simmel, G. (1970). Problemas Fundamentais da Filosofia. Coimbra: Atlântida Editora. 
Simmel, G. (2004a). Fidelidade e Gratidão e Outros Textos. Lisboa: Relógio D’Água.

Simmel, G. (2004b). Fragmento Sobre o Amor e Outros Textos. Lisboa: Relógio D'Água.

Simmel, G. (2008). Filosofia da Moda e Outros Escritos. Lisboa: Edições Texto Grafia.

Simmel, G. (2001 [1909]). "Brücke und Tür”, in Georg Simmel Gesamtausgabe. Frankfurt: Suhrkamp, vol. 12, pp. 55-61.

Simmel, G. (1913). Goethe, Leipzig: Klinkhardt.

Sousa, A; Ponte, B.; Guimarães, D. e Soeiro, E. (2004). Entrevistas a Natália Correia. Mem Martins: Zetho Cunha Gonçalves.

Vandenberghe, F. (2005). As Sociologias de Georg Simmel. São Paulo: Edusc.

Waizbort, W. (2000). As Aventuras de Georg Simmel. São Paulo: Editora 34.

\section{RESUMO}

\section{SIMMEL E A CULTURA FEMININA EM NATÁLIA CORREIA}

A primeira obra de Georg Simmel, traduzida para português e publicada em Portugal, ocorreu apenas em 1969, sob a chancela de uma pequena editora, a Galeria Panorama. O livro é constituído por quatro ensaios de Simmel: "Cultura Feminina", título que nomeia o livro, "Filosofia do Coquetismo", "Filosofia da Moda" e "O Masculino e o Feminino". Conta ainda com um Prefácio de Romeu de Melo e uma Introdução da destacada poeta e intelectual Natália Correia. O artigo centra-se na edição deste volume e incide em especial na recepção realizada por Natália Correia, que advogou uma forma peculiar de feminismo, ao pensamento de Simmel sobre a feminidade.

Palavras-chave: Natália Correia, cultura feminina, Simmel, Simmel em Portugal 